\section{$1673 f$ NETWORK ON THE COORDINATION AND HARMONISATION OF EUROPEAN OCCUPATIONAL COHORTS (OMEGA-NET)}

IS Mehlum. National Institute of Occupational Health (STAMI), Oslo, Norway

10.1136/oemed-2018-ICOHabstracts.356

OMEGA-NET is a 4 year COST Action network, starting in October 2017, funded by EU. Occupation and paid employment is an essential component of adult life and a major determinant of health and healthy ageing. However, in recent years there has been very limited coordination and promotion of European health research on occupation and employment. Europe currently has some of the most valuable occupational, industrial, and population cohorts worldwide. The lack of integration of these cohorts hampers the optimal exploitation of these resources, essential to underpin evidence-based interventions and policy. The overarching concept of OMEGANET is to create a network to optimise the use of occupational, industrial, and population cohorts at the European level. OMEGA-NET will advance i) collaboration of existing cohorts, with extensive contemporary information on employment and occupational exposures, ii) coordination and harmonisation of occupational exposure assessment efforts, and iii) facilitation of an integrated research strategy for occupational health in Europe. We will inventory numerous cohorts with occupational information in Europe; implement an online interactive tool with detailed information on existing cohorts; facilitate work on harmonisation of occupational exposure and health outcome information and new protocols for data collection; connect scientific communities on occupational health in Europe and beyond; and provide networking, leadership, and training opportunities for early career researchers in occupational epidemiology and exposure assessment. Collaboration through OMEGA-NET will enhance the scientific output from individual studies and facilitate pooled studies, data sharing, and transfer of tools and skills to make greater and more efficient use of existing cohorts. The work will provide a foundation for an enhanced evidence base for the identification of health risks and gains related to occupation and employment to foster safe and healthy preventive strategies and policies. Researchers from countries outside Europe can participate in COST Actions on the basis of ascertained mutual benefit.

\section{CHALLENGES IN OCCUPATIONAL HEALTH JOURNAL PUBLISHING}

${ }^{1} \mathrm{MR}$ Sim, ${ }^{2} \mathrm{~T}$ Guidotti, ${ }^{3} \mathrm{M}$ Härmä, ${ }^{4} \mathrm{~J}$ Hobson, ${ }^{5} \mathrm{SK}$ Kang. 'Monash University, Melbourne, Australia; ${ }^{2}$ Occupational + Environmental Health and Medicine, Washington D.C., USA; ${ }^{3}$ Finnish Institute of Occupational Health, Helsinki, Finland; ${ }^{4}$ Hobson Health, Stoke on Trent, UK; ${ }^{5}$ Gachon University Gil Medical Centre, Incheon, Rep of Korea

\subsection{6/oemed-2018-ICOHabstracts.357}

Publishing in peer reviewed scientific journals has been the traditional method to provide the research findings needed to improve occupational health practice, develop workplace exposure limits and inform policy development to better control workplace hazards. In recent years, journal publishing has faced several challenges in maintaining their influence and independence in the occupational health field. A major challenge is managing actual and perceived conflicts of interest and striking the right balance between input by industry and government in occupational health research, while preserving researcher independence. In recent years here has been a growing number of open access journals which are funded by authors paying a processing charge instead of the traditional method whereby funding comes from reader subscriptions. While there are many legitimate open access journals, this trend has given rise to what are known as 'predatory journals', which are established with the main purpose of making a profit, often having little involvement within the occupational health community and little regard for rigorous peer review. This endangers the quality of scientific publication. Another challenge for journals is how to better engage with researchers and practitioners in low and middle income countries where higher workplace hazards are more likely to occur. Content sharing to allow greater access to peer reviewed journal articles is another challenge for journals, especially as it is becoming more common for research grant bodies to require wide dissemination of the findings from studies they fund, which can conflict with journal publishing and access policies. To help editors and journals deal with the wide range of problems which can arise in the publishing process, the Committee on Publication Ethics has been established, which provides useful case studies and other resources. These issues and more will be the main focus of this workshop, with contributions by Editors from some of the main international occupational health journals.

\section{COCHRANE WORK}

Deirdre Fitz Gerald. Medmark Occupational Healthcare Cork Ireland

\subsection{6/oemed-2018-ICOHabstracts.358}

Aim of special session To introduce and promote Cochrane Work, including issues relating to the development of and quality requirements of systematic reviews.

${ }^{1} \mathrm{JH}$ Ruotsalainen, ${ }^{2} \mathrm{HF}$ van der Molen, ${ }^{3} \mathrm{TC}$ Morata, ${ }^{4}$ Prof Carel $\mathrm{T}$ Hulshof, ${ }^{5} \mathrm{R}$ Sauni, ${ }^{6}$ Deirdre FitzGerald

${ }^{1}$ Cochrane Work, Finnish Institute of Occupational Health, Kuopio, Finland

${ }^{2}$ Academic Medical Centre, University of Amsterdam, Department, Coronel Institute of Occupational Health, Amsterdam Public Health research institute, Amsterdam, The Netherlands

${ }^{3}$ National Institute for Occupational Safety and Health, Cincinnati, USA

${ }^{4}$ Netherlands Society of Occupational Medicine (NVAB), Centre of Excellence, Utrecht, the Netherlands; Academic Medical Centre, dept. Coronel Institute of Occupational Health, Amsterdam, The Netherlands

${ }^{5}$ Department for Occupational Safety and Health, Ministry of Social Affairs and Health, Finland

${ }^{6}$ Medmark Occupational Healthcare, Cork, Ireland

\section{0a THE PICO QUESTION IS TO A COCHRANE REVIEW LIKE THE THICK CREAMY HEAD IS TO A PINT OF GUINNESS}

JH Ruotsalainen. Cochrane Work, Finnish Institute of Occupational Health, Kuopio, Finlan

\subsection{6/oemed-2018-ICOHabstracts.359}

Introduction Conducting Cochrane reviews and updating them regularly requires a considerable investment from authors and 
the editorial base alike. It is therefore important that the reviews that are eventually published provide the most informative answers to the most relevant questions to guide decision-making. Asking vague questions leads to vague answers and is a waste of time, money and resources.

Methods Any question arising from practice that has to do with choosing a suitable intervention for a particular health issue can be formulated to contain the elements $\mathrm{p}=$ Participants, $\mathrm{I}=$ Intervention(s), $\mathrm{C}=\mathrm{Control}$ and $\mathrm{O}=$ Outcome(s). Similarly, a research study evaluating the effectiveness of a particular intervention and a systematic review aiming to make a summary of all sufficiently similar studies ought to use this recipe. This talk will explore how each of these elements influence the whole review process from searching studies to making a synthesis of their findings and reporting results.

Result We will compare a convenience sample of five recent Cochrane Work reviews with another five recent nonCochrane reviews for their use of PICO and how it is implemented throughout the review.

Discussion PICO is a simple tool that will ensure that research will answer the question of interest that has arisen from practice. Ignoring PICO almost certainly leads to a biassed review process and consequently biassed review results. PICO is the most important ingredient in enabling evidence-based medicine.

\section{0b GRADE APPLIED IN A RECENT UPDATED COCHRANE REVIEW}

${ }^{1} \mathrm{HF}$ van der Molen, ${ }^{2} \mathrm{P}$ Basnet, ${ }^{2} \mathrm{HH}$ Verbeek. ${ }^{1}$ Academic Medical Centre, University of Amsterdam, Department: Coronel Institute of Occupational Health, Amsterdam Public Health research institute, Amsterdam, The Netherlands; ${ }^{2}$ Cochrane Work Review Group, Finnish Institute of Occupational Health, Kuopio, Finland

\subsection{6/oemed-2018-ICOHabstracts.360}

Evaluation of interventions to reduce occupational injuries in the construction industry are relatively scarce. Various interventions to prevent occupational injuries have been proposed and studied. In a Cochrane review we systematically summarise the most current scientific evidence on the effectiveness of interventions to prevent injuries associated with construction work. Most of these studies are analysed with an interrupted time series design, which are characterised by a higher risk of bias.

We use the GRADE (Grades of Recommendations, Assessment, Development and Evaluation) approach that systematically represents the factors important in interpretating evidence and results in a current update of our review. While the evidence can be different for each outcome, GRADE considers the evidence for each outcome and takes into account the magnitude of effect and ensures the process is systematic and transparent.

Rating of the evidence was done as follows: with RCTs we started at high quality and with observational studies we started at low quality. Then we downgraded if one of the following criteria were met: study limitations, inconsistency, indirectness, imprecision and publication bias. We upgraded observational studies if there have been dose-response, large effect size or an opposite effect of confounding. We constructed tables for every comparison for our interventions and our two primary outcomes fatal and non-fatal injuries because these were our inclusion criteria for the studies.

Applying GRADE and the difference with strength of association will be discussed based on the above mentioned update of our review. Also the differences in clarity of the conclusions with and without GRADE will be discussed.

\section{C UNEXPECTED INVITATION TO BECOME A CO-AUTHOR OR: HOW I LEARNED TO STOP WORRYING AND LOVE SYSTEMATIC REVIEWS}

TC Morata. National Institute for Occupational Safety and Health, Cincinnati, USA

10.1136/oemed-2018-ICOHabstracts.361

All of us are recipients of health care, and most of the ICOH Congress participants also provide health services. As patients and providers we expect that the service being rendered stands on a solid scientific base. Nowadays, with the expansion of publications and communication channels, we hear a lot about evidence-based practice (EBP) and systematic reviews. Systematic reviews, are the most important type of scientific review because they are central to evidence-based practice, but they can be misunderstood or even intimidating to some. Examination of the contributions of systematic reviews to occupational health and the processes to get familiarised, became a user and participate in the implementation of evidence-based practices to prevent work-related disorders. Locating pertinent Cochrane resources and reviews, and defining what are answerable questions and eligible sources of evidence for a Cochrane Review. Examples will focus on a Cochrane review that examined the effectiveness of enforcement tools for preventing occupational diseases and injuries and a second one that examined interventions to promote the use of hearing protections and other efforts to control noise and promote hearing loss prevention. To be able to offer evidence-based practices, occupational health professional need to recognise the need and approaches that will allow him/her to be a lifelong learner, by keeping current with evidence-based professional practice, and engage in continuing competence and professional development activities.

Disclaimer The findings and conclusions in this abstract have not been formally disseminated by the National Institute for Occupational Safety and Health and should not be construed to represent any agency determination or policy.

\section{$1710 \mathrm{~d}$ SYSTEMATIC REVIEWS AND EVIDENCE-BASED GUIDELINES, TWO OF A DIFFERENT KIND?}

Carel T Hulshof. Netherlands Society of Occupational Medicine (NVAB), Centre of Excellence, Utrecht, the Netherlands; Academic Medical Centre, dept. Coronel Institute of Occupational Health, Amsterdam, the Netherlands

\subsection{6/oemed-2018-ICOHabstracts.362}

In improving the quality and professional independence of Occupational Safety and Health (OSH) professionals, the development of an evidence-based practice plays a pivotal role. OSH professionals should strive to use scientific evidence as much as possible to support their decisions in daily practice and policy. However, in many situations, still a gap between evidence from research and decision-making in daily practice 